\title{
Técnicas neurocientíficas como medio de prueba pericial ${ }^{*}$
}

\author{
Fernando Luna Salas ${ }^{\mathrm{a}}$
}

Resumen: El presente trabajo jurídico-reflexivo, cuyo abordaje se hace desde la perspectiva cualitativa con una revisión bibliográfica-documental, tiene como objetivo revisar la eventual utilización probatoria de ciertas técnicas neurocientíficas dentro de los procesos judiciales, así como la forma de valoración judicial de este medio probatorio.

Palabras clave: prueba pericial; técnicas neurocientíficas; neurociencia; valoración; factores Daubert

Fecha de recepción: 19 de junio de 2019 Fecha de evaluación: 25 de junio de 2019

Fecha de aprobación: 4 de julio de 2019

Cómo citar: Luna Salas F. (2019). Técnicas neurocientíficas como medio de prueba pericial. Revista Prolegómenos, 22(44), pp. 143-154. DOI: https://doi.org/10.18359/prole.4160

* El presente artículo de investigación surge de la investigación "Técnicas neurocientíficas como medio de prueba pericial". En esta, el autor actuó en calidad de investigador principal y fue financiado por recursos propios dentro del Semillero de Investigación Ciencia y Proceso de la Facultad de Derecho de la Universidad de Cartagena, que está adscrito al grupo de investigación Filosofía del derecho, derecho internacional y problemas jurídicos contemporáneos de la misma Facultad.

a Magíster en Derecho de la Universidad de Cartagena y Especialista en Derecho Procesal de la Universidad Libre. Abogado y Profesor Investigador de las cátedras de Derecho Procesal Civil General y Especial, Derecho Probatorio y Neurociencia y Derecho de la Universidad de Cartagena y de la Fundación Tecnológica Antonio de Arévalo (Tecnar). Editor asociado de la Revista Jurídica Mario Alario D’ Filippo. Coordinador y jurídico de proyectos de intervención y de cooperación internacional sobre víctimas y comunidades indígenas. Director del semillero de investigación Ciencia y Proceso y coinvestigador del semillero de investigación Neurociencia y Derecho, los cuales están vinculados al grupo de investigación Filosofía del derecho, derecho internacional y problemas jurídicos contemporáneos de la Facultad de Derecho de la Universidad de Cartagena. Miembro de la Asociación Colombiana de Derecho Procesal Constitucional (ACDPC) y Director del Capítulo Regional Bolívar de la misma asociación.

Correo electrónico: flunas@unicartagena.edu.co ORCID: https://orcid.org/0000-0003-4574-6335. 


\title{
Neuroscientific Techniques as Expert Evidence
}

\begin{abstract}
This legal reflection paper, with a qualitative approach and desk research as a method, intends to review the potential evidentiary use of certain neuroscientific techniques within court proceedings, as well as the judicial assessment of this evidence.
\end{abstract}

Keywords: Expert evidence; neuroscientific techniques; neuroscience; assessment; Daubert standard

\section{Técnicas neurocientíficas como meio de prova pericial}

Resumo: O presente trabalho jurídico-reflexivo, cuja abordagem é feita a partir da perspectiva qualitativa com uma revisão bibliográfico-documental, tem como objetivo revisar o possível uso probatório de certas técnicas neurocientíficas nos processos judiciais, bem como a forma de avaliação judicial desse meio probatório.

Palavras-chave: prova pericial; técnicas neurocientíficas; neurociência; avaliação; Fatores de Daubert 


\section{Ciencia novel}

Una hipótesis que ha tenido gran acogida es aquella que contempla la eventual utilización probatoria de ciertas técnicas neurocientíficas. Entiéndase la neurociencia como la ciencia que se ocupa de estudiar la organización funcional del sistema nervioso central, es decir, del cerebro. Dicho sistema está compuesto, además, por la médula espinal y los nervios periféricos. El cerebro se compone del tronco, del encéfalo y de los hemisferios cerebrales. Así mismo, de la corteza cerebral, que es fundamental para acciones voluntarias como el lenguaje, el habla y otras funciones superiores como el pensamiento y la memoria. Dejando de lado estos términos técnicos, por el momento, es importante anotar que la comunidad científica coincide en afirmar:

Todavía queda mucho por descubrir y aprender $y$, fundamentalmente en aspectos tan importantes como la conciencia; por lo que el estudio de la corteza cerebral y las funciones en las que está implicada es uno de los campos de investigación más activos y excitantes dentro de las Neurociencias. (Asociación Británica de Neurociencias, 2003, p. 5)

De acuerdo con Sanguinetti (2014, p. 7), la neurociencia se ocupa de estudiar fenomenos como la percepción, la inteligencia, el lenguaje, las emociones, la conciencia, el yo, las decisiones, las preferencias morales, la estética y la educación.

Para los efectos de este trabajo nos interesa situarnos en lo relativo a la neurociencia cognitiva, que según Casafont $(2014$, pp. 15, 17) se encarga de estudiar los mecanismos biológicos que se producen en nuestros procesos mentales y sus manifestaciones conductales. A propósito de ello, también se señala que los tres campos configurativos de nuestras vivencias son el pensamiento, el sentimiento y el comportamiento.

Esta ciencia novel, que está aún en desarrollo y en etapa de estructuración científica, niega o contradice muchas tesis de la filosofía, la psicología y la ciencia jurídica, especialmente, en el campo del derecho penal. En palabras de Michele Taruffo, el problema que podríamos encontrar se refiere a la "determinación de su efectiva relevancia para la declaración de los hechos que son objeto de prueba y decisión en el juicio" (2013, p. 15). González Lagier (2018, p. 43 y 44), por su parte, considera que existen tres retos que la neurociencia plantea específicamente para el derecho penal: el problema del libre albedrío, el de la reducción de los estados mentales a meros procesos neuronales y el de la reducción de la normatividad a una especie de leyes de la naturaleza.

El profesor González Lagier (2015) manifiesta que el desarrollo espectacular que están teniendo las investigaciones sobre el funcionamiento del cerebro - la neurociencia - tiene importantes repercusiones para la adscripción de la responsabilidad moral y jurídica. Por un lado, estas investigaciones plantean el problema de si nuestras acciones cumplen los requisitos que la teoría clásica de la responsabilidad exige: libertad de acción (que nuestras acciones sean consecuencias de la combinación de nuestros deseos con las creencias acerca de cómo satisfacerlos) y libertad de voluntad (que esos deseos y creencias sean a su vez, al menos en cierto grado, libres y controlables por el agente). Por otro lado, parecen ofrecer nuevas técnicas para la prueba de los hechos - o algunos de ellos-, que generan esa responsabilidad (técnicas que genéricamente podríamos llamar "neuro-pruebas").

\section{Neurociencia y derecho}

Se han analizado los quehaceres jurídicos a partir del campo de las neurociencias y de esto se ha obtenido un mundo de posibilidades. Un ejemplo de ello es lo referente a la autonomía de la voluntad, pilar y principio básico jurídico: los estudios realizados por un grupo de neurocientíficos apuntan a la no existencia del libre albedrío, cuya base es esa autonomía de la voluntad. Si esto fuera así se reformaría la forma de pensar el derecho penal y el civil.

Así mismo, se desarrollan temas como la capacidad, el área de la verdad y falsedad. Los resultados de este debate podrían estar relacionados con la idea de veracidad de las declaraciones de los testigos. En este sentido, incluso se ha llegado a hablar de una neurofilosofía y de una neuroética.

El año 2004 marcó un punto de partida importante para la vinculación de la neurociencia y el derecho con la aparición del texto Neuroscience 
and the Law Brain, Mind, and the Scales of Justi$c e^{1}$, libro que quizá dio lugar a una aproximación de lo que podría ser el neuroderecho en el common law. Este es el momento preciso para resaltar cómo el sistema jurídico anglosajón lleva ventajas al civil law, que aún se muestra escéptico frente al tema, quizás por temor a recorrer un plano poco explorado.

Para comprender la interacción entre ambas ciencias, se entenderá que el cerebro y en general el sistema nervioso central originan y condicionan la conducta humana, que es objeto de estudio para el derecho y, a su vez, está regulada por los sistemas jurídicos. Antes del desarrollo de esta ciencia era impensable, por ejemplo, cuestionar con fundamentos - desde una perspectiva científica y no filosófica- la idea de libre albedrío, asunto que ahora es bastante discutido e incluso ha llegado a replantear y a debatir por algunos juristas las tan cimentadas teorías del derecho penal. Haciendo un paréntesis - que mucho y poco tiene que verhay estudiosos del derecho que hablan del fin de la noción de responsabilidad, porque se ha demostrado la inexistencia de la llamada "voluntad". Así, este sería el final o por lo menos el comienzo de una restructuración del derecho penal, incluso del derecho en general (Taruffo, 2013). Tales son los postulados de los denominados neurofilósofos.

Por esa razón, estos y los futuros descubrimientos de la neurociencia deberían modificar o nutrir las instituciones jurídicas que se conservan hoy día, más por la tradición que por cimientos científicos desarrollados a cabalidad. Dichos descubrimientos también podrían contribuir con aportes neurocientíficos al esclarecimiento de procesos judiciales, específicamente con la posible utilización de técnicas neurocientíficas como medios de prueba dentro de la jurisdicción, situación que posibilitaría brindar mejores herramientas probatorias

1 En este libro se plasman, de forma resumida, las deliberaciones que se llevaron a cabo en una reunión de veintiséis neurocientíficos, juristas, abogados y jueces para resolver los problemas relacionados con los descubrimientos en la neurociencia y como estos pueden influir en los procedimientos legales, penales y civiles. a los jueces, con el fin de poder llegar a un mejor grado de probabilidad en la confirmación o negación de las proposiciones-hechos- expuestos por las partes.

Son varios los campos en los que el derecho necesita de la neurociencia; por ejemplo, en temas cruciales como la determinación de la capacidad, la imputabilidad, la imparcialidad del juez, la voluntad, la responsabilidad jurídica, la veracidad de un testigo o la determinación de si hubo error como vicio del consentimiento. Nada de esto podría ser tratado por el derecho tan profundamente sin una explicación neurocientífica, que explore cómo funcionan estos aspectos en el cerebro y, por lo tanto, en la conducta. Todo ello, repetimos, implica una transformación de la cultura jurídica.

En el afán de interconectar estas ciencias, se fundó el Instituto de Neurociencias y Derecho $(\mathrm{INeDe})^{2}$. Este tiene una visión canalizadora y consensuada entre juristas y neurocientíficos, ya que analizan el modo y el ámbito en que los estudios sobre el funcionamiento del sistema nervioso pueden ser utilizados en el sistema legal, de manera válida y eficazmente.

A este punto de la investigación se hace más difícil negar el vínculo y grado de interacción que existe entre neurociencia y derecho, puesto que esta discusión es interdisciplinaria y trasciende fronteras. Es así como el debate queda planteado y no puede ser ignorado por la comunidad jurista colombiana o foránea.

\section{Técnicas neurocientíficas}

Esta ciencia trae consigo una serie de técnicas psicoanalíticas relacionadas con las neuroimágenes, que pueden permitir superar los problemas de la prueba de los hechos psicológicos, pues los trata como hechos empíricos y no como ficciones normativas, levantando así su velo de subjetividad.

2 Este propone promover la investigación científica para examinar las posibles interacciones bidireccionales entre el mundo del derecho de los recientes hallazgos en el estudio del cerebro, sin perder de vista sus limitaciones. Ver www.fundacionineco.org/instituto-de-neurociencias-y-derecho/ 
Las siguientes técnicas han sido el resultado de los grandes avances tecnológicos en este campo de la neurociencia, como lo explica Sanguinetti (2014, pp. 87 y 177): todo ello es posible gracias al descubrimiento de que una neurona es una célula nerviosa completa que se constituye en la "unidad morfofuncional básica del sistema nervioso". El fenómeno denominado "descarga de espigas o potenciales de acción" no es otra cosa que la "producción de potenciales de acción por el cono axónico de una neurona como respuesta a una determinada entrada de estímulos a esta misma neurona".

A continuación, se describen las técnicas:

- La tomografía por emisión de positrones (PET): esta técnica consiste en que por medio de radioisótopos de átomos que emiten positrones, luego de colisionar estos con electrones de carga negativa, producen una emisión de rayos gamma por medio del cual se rastrea, mide y analiza a través de un sistema computarizado que genera imágenes tomografías de los fenómenos electromagnéticos que ocurren en el sistema neuronal cerebral. (Gómez Pavajeau. 2017, p. 250).

- La tomografía axial computarizada: esta técnica obtiene imágenes por medio de una síntesis realizada por una computadora, a partir de los datos arrojados por la trasmisión en un plano de una fina radiación $\mathrm{X}$ de forma circular, que se mide en el lado opuesto al de la emisión por medio de un contador de centelleo (Mora y Sanguinetti. 2004, p. 275).

- La magnetoencefalografía: es una técnica que registra la actividad funcional cerebral, mediante la captación de campos magnéticos, y así permite investigar las relaciones entre las estructuras cerebrales y sus funciones.

- La resonancia magnética funcional o nuclear (FMRI): esta es una de las técnicas más avanzadas, pues permite detectar los cambios en el flujo sanguíneo del cerebro en el momento en que el individuo realiza determinadas tareas motoras o está en ciertos estados cognitivos o emocionales. Aquello posibilita correlacionar estados mentales con estados cerebrales, de manera que, ante la presencia de un estado cerebral determinado, se puede suponer la existencia de un estado mental correspondiente. Esta técnica es sensible a los cambios del flujo sanguíneo cerebral asociado a la actividad neuronal. Usa las propiedades paramagnéticas de la desoxihemoglobina endógena como marcador (Mora y Sanguinetti, 2004, p. 243).

- Magnetoencefalografía (MEG): es una técnica no invasiva que registra la actividad funcional cerebral, mediante la captación de campos magnéticos, permitiendo investigar las relaciones entre las estructuras cerebrales y sus funciones.

- Pletismógrafo del pene: técnica para establecer cuál es la actividad libidinosa ante la exposición de imágenes, por ejemplo, de niños (Villamarín, 2014, p. 9).

- P300: Lawrence Farwell construyó el primer sistema de interfaz cerebro computadora y el método llamado huellas digitales cerebrales (brainfingerprinting) o evaluación computarizada del conocimiento (CKA), técnica con la cual se puede detectar la activación inducida en el cerebro de alguien que observa una imagen o una escena impresa en la memoria, para así deducir, por ejemplo, que está mintiendo si al verla afirma que no la conoce o comprobar, al contrario, que está diciendo la verdad (Gómez Pavajeau, 2017, p. 275).

Villamarín (2014) explica que las técnicas PET y FMRI resultan ser no invasivas y sirven para el estudio de las áreas cerebrales que se activan cuando se realiza una tarea específica o se somete al sujeto a ciertos estímulos. Esto debido a que:

Las neuronas en el cerebro se encienden eléctricamente, formando una especie de red de circuitos eléctricos, puesto que ciertos sucesos sensoriales, motores o cognitivos provocaban fluctuaciones en el electroencefalograma, lo que se denominó potenciales de evocación (p.83). 


\section{La neurociencia como medio de prueba pericial científica}

Los neurocientíficos consideran que, a través de las técnicas que se relacionaron anteriormente, se puede demostrar, entre otras cosas, lo siguiente:

Por una parte, se puede estabecer si una persona dice la verdad o no. Se trata de algo parecido al famoso detector de mentiras, pero su funcionamiento depende de técnicas neurocientíficas, en las que se controlan las variaciones de los flujos sanguineos en el cerebro de la persona examinada.

En relación con la onda P300-brainfingerprinting, Villamarín (2014, p. 89, 116 y ss) explica que la técnica de Farwell trata de someter al sujeto a un encefalograma, por medio del uso de sensores puestos en su cuero cabelludo para poder medir de forma no invasiva la respuesta de su cerebro a ciertos estímulos que se le presentan y están relacionados con el delito del que se le acusa o con el que se vincula. El test detecta de forma objetiva lo que ha grabado el cerebro sobre los hechos, sin afectar en lo más mínimo la honestidad o sinceridad del sujeto. Por su parte, Taruffo señala que "aun admitiendo que una determinada actividad cerebral sea necesaria para mentir (al igual que para decir la verdad), [...] resulta conceptualmente imposible identificar la mentira con esa actividad [...]. Las mentiras no suceden en el cerebro" (2013, p. 22).

Otro aspecto que debe también señalarse es que "las intenciones no son procesos cerebrales y, del mismo modo, la intencionalidad no se 'coloca' en una zona del cerebro y no se reduce a un estado cerebral". Así mismo, "la conciencia no es algo que 'sucede' en el cerebro, como la digestión se produce en el estómago, sino que implica el contacto con el mundo exterior, en una compleja interacción de cerebro, cuerpo y mundo (Taruffo, 2013, p.22).

Se puede pensar, entonces, que todas estas identificaciones, en definitiva, "incurren en una falacia fundamental, que consiste en atribuir a una parte del sujeto humano, es decir, al cerebro, habilidades y funciones que son propias del sujeto en su totalidad, con toda la complejidad que se manifiesta en la vida" (Taruffo, 2013, p. 23).

Ahora bien, por otra parte, la intensidad o el nivel de dolor físico que una persona siente se puede determinar y medir; estaríamos caminando por la senda de la objetivación del dolor (Junoy, 2013), ya que, como bien sabemos, este es un hecho fudamentalmente subjetivo.

En un escenario, cinco voluntarios son sometidos a sumergir sus manos por el mismo período de tiempo en un recipiente que contiene agua extremadamente fría. Efectivamente, los cinco sujetos sienten dolor, pero no en la misma intensidad - grado de dolor-, lo cual obedece a la teoría de que este es una percepción, es decir, que tiene una condición subjetiva. Entonces, indudablemente el dolor existe, pero se experimenta de manera distinta, según cada; se trata de un fenómeno que no es sencillo de explicar y mucho menos entender.

La neurociencia explica cómo es percibido el dolor en el cuerpo de la siguiente manera:

múltiples variedades de receptores, distribuidos por todo nuestro cuerpo, están sintonizados con diferentes aspectos del mundo somatosensorial (tacto, temperatura, posición del cuerpo), mientras que otros se encargan de percibir el dolor. El poder de discriminación de estos receptores varía en función de la zona del cuerpo, siendo extremadamente sensibles, entre otros, en las yemas de los dedos. La exploración activa es también muy importante, ya que interactúa directamente con el sistema motor. El dolor nos informa y nos advierte del daño causado a nuestro cuerpo. Tiene un gran impacto emocional y está sujeto a un gran control por parte del cuerpo y del cerebro. (Asociación Británica de Neurociencias, 2003, p. 13)

En consecuencia, es razonable que las teorías de responsabilidad del derecho hagan referencia a la indemnización del sujeto al que se le ha causado un daño, con el fin de revertirlo. Sin embargo, en el fondo, se podría decir que en realidad lo que se quiere no es revertir el daño, porque esto es fácticamente casi imposible, sino pagar al sujeto por el dolor causado. De ahí que lo correcto sería cuantificar el dolor y no el daño.

Continuando con la explicación, estos estudios han revelado que el dolor no es un sentido exclusivo de la piel, pues este se encuentra íntimamente asociado al sistema nervioso, tal como lo explica la Asociación Británica de Neurociencias (2003): este 
constituye en realidad un sistema con funciones y organización anatómica totalmente diferentes. Su mayor característica es que se trata de un sentido que aporta sensaciones desagradables y varía dependiendo de la persona; sorprendentemente, sus receptores proveen una información limitada sobre la naturaleza del estímulo (p.14).

Sin embargo, no hay que dejar de lado que hay otros factores que pueden afectar la percepción del dolor. Para ello hay que distinguir entre el sistema que procesa las emociones y aquel sistema del cerebro dedicado a procesar las sensaciones dolorosas. Cuando hay emociones opuestas a las negativas, esto es, tranquilidad, serenidad, empatía y seguridad, estas pueden hacer que un dolor se sienta menos (Rocha, 2013).

Esta teoría se puede fundamentar en un suceso: si a un hombre en plena guerra le fue amputado el brazo y, pese a esas circunstancias, continúo socorriendo a sus demás compañeros, él manifiesta que no sintió dolor. Existe, además, otro ejemplo, tomado del mismo escenario de los recipientes de agua extremadamente fría, que ya habíamos mencionado: durante el experimento se utilizaron ciertos métodos de distracción con cincos sujetos diferentes. Quienes fueron sometidos a esta variante - la distracción - lograron tener una mayor resistencia al dolor.

De toda esta exposición es claro que las neurociencias tienen por objeto de estudio la comprensión del sistema nervioso, que podría explicarse de forma metafísica como el estudio del sistema mediante el cual funciona la mente humana, científicamente abordado. Todo esto trabaja con el presupuesto de que las neuronas actúan en función del entorno en el que interactúa el sujeto.

El valor de aquello reside en que si se puede determinar la intensidad del dolor de una persona a través de la neurociencia, podríamos tomar la prueba científica como criterio para determinar la cantidad del daño que se sufre y asignarle una valoración económica e indemnizable por parte de juez.

Otro debate de la neurociencia se concentra en el problema de la voluntad y la libertad, pues para una gran parte de los neurocientíficos, estas características, atribuidas a las personas, no existen.
Afirman que lo que se conoce como voluntad es una manera de interpretar fenómenos que no son ni morales, ni jurídicos, ni psicológicos, sino problemas neuronales, ya que todo se origina en el cerebro. La voluntad es, entonces, una ilusión, una ficción y solo existen las descargas eléctricas neuronales. De esto puede surgir una aporía ${ }^{3}:$ ¿somos realmente libres o estamos determinados? (Molina, 2013).

A partir de esto, nos podríamos preguntar qué relevancia tiene para el derecho que la neurociencia considere o afirme que la voluntad sea una ilusión y, por ende, el libre albedrío no exista; en lugar de ello, solo hay impulsos cerebrales que nos determinan. Si esta tesis es acertada, tendríamos que reescribir casi todo el derecho penal, ya que los conceptos básicos de esta rama del derecho tienen como base la voluntariedad de la conducta. $\mathrm{Si}$ esta, en realidad, es determinada por el cerebro, no existiría la culpa y, por lo tanto, tampoco la responsabilidad.

Tal es la tesis del determinismo, según la cual la voluntad está determinada por la actividad neuronal de una parte del cerebro. Así pues, no tendría sentido hablar de la voluntariedad del comportamiento criminal, ni tampoco clasificar las conductas en voluntarias e involuntarias (Taruffo, 2013, p. 19). De igual forma, en el campo del derecho civil, no podríamos decir que el contrato está viciado porque faltaba la voluntad de una de las partes.

Sin lugar a duda, aquella tesis determinista está fundamentada en experimentos científicos, como el de Libet (Lagier, 2013), que llegó a demostrar que la decisión consciente de realizar cualquier movimiento viene precedida de cierta actividad eléctrica en el cerebro, que es el que toma la decisión por su cuenta, antes de que seamos conscientes de ella. Sin embargo, existen autores como Peter Strawson (1995) que han tratado de mostrar la imposibilidad de confirmar la existencia de un determinismo, a través de la constatación científica. Para el autor, las actuaciones y decisiones del individuo obedecen a comportamientos aprendidos en su relación con los otros, es decir, en la interacción de la vida

3 Paradoja o dificultad lógica insuperable. 
social, y no son producto de mandatos eléctricos cerebrales.

Ahora bien, como sabemos, uno de los medios probatorios existentes en los procesos judiciales es el dictamen pericial, en el que el administrador de justicia, valiéndose de los conocimientos específicos de un tercero sobre un área o materia en concreto, soporta su decisión judicial.

$\mathrm{Si}$ antes podíamos afirmar que la prueba reina sin lugar a duda era la confesión, hoy en día, con los avances de la ciencia y la tecnología, esa afirmación es susceptible de ser replanteada, considerando que una de las pruebas que en mejor medida le aporta y le contribuye al proceso, en la búsqueda y obtención de esa gran probabilidad de verdad, son las pruebas periciales de carácter científico.

En el proceso se busca que una persona ajena a este, llamada perito o experto, verifique las proposiciones contempladas por cada extremo de la litis en su demanda y contestación, ya que aquellas, pertinentes para el caso, requieren ser evaluadas por alguien con especiales conocimientos científicos, técnicos o artísticos.

En Colombia, como en muchas otras latitudes jurídicas, la prueba pericial puede ingresar al proceso por dos vías: ya sea a través de los peritos de confianza o de los seleccionados por el juez o gracias a que las partes aportaron dicha prueba. Esta última opción es frecuente en los sistemas orales, y su fin es materializar los principios de celeridad y concentración.

De igual forma, vemos que la principal forma en la que se materializa el principio de contradicción dentro de los procesos, con relación a las pruebas periciales, es a través del testimonio del experto en audiencia, cuya exposición es importantísima, en cuanto ella servirá a las partes para refutar y contrarrestar, a través de otro dictamen pericial y, sobre todo, a través de un interrogatorio, lo manifestado por el perito dentro de su experticia. Además, es un momento crucial para que el juez pueda indagar, aclarar y complementar su análisis y, de este modo, tenga más herramientas argumentativas que le sirvan a la hora de valorar en conjunto todas las pruebas. Así, puede llegar a una conclusión acorde con lo fáctico y con el derecho.
Las técnicas de neuroimágen deben considerarse como una prueba pericial, específicamente como una prueba novel, de las que se estipulan dentro del artículo 422 de la Ley 906 de 2004, el cual reza lo siguiente:

Artículo 422: Admisibilidad de publicaciones científicas y de prueba novel. Para que una opinión pericial referida a aspectos noveles del conocimiento sea admisible en el juicio, se exigirá como requisito que la base científica o técnica satisfaga al menos uno de los siguientes criterios:

1. Que la teoría o técnica subyacente haya sido o pueda llegar a ser verificada.

2. Que la teoría o técnica subyacente haya sido publicada y haya recibido la crítica de la comunidad académica.

3. Que se haya acreditado el nivel de confiabilidad de la técnica científica utilizada en la base de la opinión pericial.

4. Que goce de aceptabilidad en la comunidad académica.

En ese artículo se adoptó el criterio de la Corte Suprema de Justicia de los Estados Unidos, que profirió una providencia mejor conocida como sentencia Daubert (1993), y estableció los parámetros que deben ser tenidos en cuenta por el juez a la hora de valorar una prueba científica allegada por un experto. El juez Blackmun, dentro de esa sentencia, planteó cuáles son las condiciones mínimas que deben existir para hablar de ciencia en un aspecto procesal, así como también manifestó que no se debe admitir el peritaje si no se cumplen ciertos requisitos epistemológicos:

La publicación en revistas sujetas a revisión: la Corte Suprema advirtió, en relación con este criterio, que no había un vínculo necesario con la fiabilidad del conocimiento científico y, por ello, no debía considerarse como condición sine qua non para la admisión de las pruebas que se pretendieran incorporar al proceso. Sin embargo, afirmó que la revisión por pares y/o la publicación sí incrementaban las posibilidades de encontrar errores metodológicos sustantivos en aquellas y, por tanto, permitían evaluar mejor su fiabilidad (Vázquez, 2015, p. 115). 


\section{Del conocimiento de la probabilidad efectiva o} potencial de error: es indispensable que las técnicas periciales sean sometidas a análisis científicos y empíricos o a estudios controlados, que demuestren su válidez o fiabilidad, y no que sean soportadas exclusivamente con citaciones bibliográficas que soporten solo simples argumentos de autoridad. Únicamente a partir de estos estudios se puede evidenciar el rango de error existente en estas técnicas. Hay que descubrir o saber cuáles fueron las fuentes de error con las que pudo trabajar el experto.

El "Strengthening Forensic Science in the United States: A Path Forward” (2009) conceptuó:

Una agenda de investigación completa debe incluir estudios para establecer las fortalezas y limitaciones de cada procedimiento, fuentes de sesgos y variación, cuantificación de las incertezas creadas por estas fuentes, mediciones del rendimiento, los pasos procedimentales en el proceso de analizar pruebas forenses y los métodos para continuar monitoreando y mejorando los pasos de tal proceso. (p. 188)

La necesidad de que toda tesís científica sea sometida a intentos de falsificación y refutación: en este punto, el juez Blackmun se basa, por un lado, en el filósofo austríaco Karl Popper, con su corriente epistemológica del falsacionismo o principio de falsabilidad ${ }^{4} \mathrm{y}$, por otro, en el filósofo de la ciencia, Carl Hempel (1966), en relación con su idea de que "los enunciados que constituyen una explicación científica deben ser susceptibles de contrastación empírica" (p.76).

Este factor sostiene que, para poder admitir una prueba científica al procedimiento, las hipótesis que esta prueba sostenga han de haber sido sometidas a intentos de refutación luego superados.

La aceptación de la ciencia y de la técnica en el ámbito de la comunidad científica de referencia: se trata de un estándar existente en Estados Unidos desde 1923, cuando la Corte de Apelaciones del Distrito de Columbia resolvió la apelación

4 Posibilidad abstracta de que una hipótesis sea sometida a alguna prueba que pudiera mostrar su falsedad. del caso Frye v. United States. Sin duda, aquel constituye un cambio importante en los criterios de valoración de las pruebas periciales, pues va más allá de las calidades del experto y valora un aspecto sobre el conocimiento que fundamenta la técnica aludida. Es, pues, un importante giro epistemológico en la experiencia estadounidense, que hizo énfasis en la información que se usa para la determinación de los hechos y no en el sujeto que brinda dicha información.

Aquí lo relevante no es tanto la publicación, sino lo que ha dicho la comunidad experta en relación con esa publicación y con la técnica empleada. El juez debe evidenciar cuál es la reacción de la comunidad científica o experta en torno a esa publicación; la válidez o el respaldo que le han otorgado.

El caso Daubert y sus factores para valorar la admisibilidad de las pruebas periciales presentadas por los expertos es el más significativo para toda la comunidad jurídica en general. A partir de esta jurisprudencia se crea un hito jurídico, que demarca y sirve de fundamento epistemológico para todos los administradores de justicia, que podrán basarse en ella para intentar dilucidar cuándo una prueba pericial científica puede y debe ser admitida. Para el caso de otras latitudes como la nuestra, sirve para que el juez pueda hacer un mejor análisis crítico de la prueba que el experto le presenta al momento de realizar su valoración o, como ocurre en el ambito penal, para admitir que una prueba de esta categoría pueda ir a juicio oral.

De igual forma, otro punto que se podría traer a colación dentro de este trabajo es lo concerniente a la valoración de las pruebas científicas. Sin querer ahondar mucho en este punto, que haría parte de otra investigación, se puede decir que "el juez está llamado a convertirse en custodio del método científico, a los fines de distinguir entre buena y mala ciencia, es decir, debe ocupar la posición de garante de la admisibilidad de las pruebas científicas desde la perspectiva metodológica, procurando siempre determinar la fiabilidad de las pruebas, sean estas científicas o no" (Luna, p. 133).

En la utilización de esta clase de técnicas, se vislumbra la presencia de ciertas inquietudes que 
tienden, por un lado, a su fiabilidad y precisión probatoria y, por otro, a lo relativo al tratamiento ético y jurídico. A partir de ello, podríamos hacernos varios interrogantes: $\dot{i}$ se requiere el consentimiento del sujeto para que las pruebas neurocientíficas sean jurídicamente aceptables? ¿El derecho de defensa se vulnera con esta clase de pruebas? ¿Las pruebas neurocientíficas equivalen a una confesión? ¿Afectan a la dignidad de la persona este tipo de pruebas?

En relación con esos interrogantes de índole constitucional, y sin querer profundizar en esa temática que será producto de otra investigación, se puede plantear que, desde una óptica garantista, deben existir argumentos que tiendan a salvaguardar la dignidad e integridad de la persona en cada una de las circustancias planteadas anteriormente.

Las técnicas de neuroimágenes, sin duda, pueden servir como prueba pericial dentro de un proceso judicial, con el fin de que el juez pueda soportar mucho mejor su decisión. No obstante, de acuerdo con la normatividad existente, siguiendo los parámetros y la salvaguarda de los preceptos constitucionales, y en virtud del control de convencionalidad, se requiere el consentimiento libre y consciente de quien se va a someter a dichos exámenes, con el fin de validar y otorgar legitimidad al método que se empleará.

Manifiesta Villamarín (2014, p. 106) que, en Francia, las técnicas de imagen cerebral pueden ser utilizadas con fines médicos, de investigación científica y en el marco de pruebas judiciales, con tal de que, como lo estipula el artículo 45 de la Ley 814 de Bioética de julio 7 de 2011, se cuente, por escrito, con "el consentimiento expreso de la persona que va a ser sometida a examen, después de habérsele informado su naturaleza y finalidad. El consentimiento ha de mencionar la finalidad del examen. Es revocable sin que se exija ningún requisito especial de forma y en todo momento".

La clave de la admisibilidad de este tipo de medios probatorios se debe centrar, entonces, en que la técnica haya sido aplicada al sujeto de manera consciente, libre, voluntaria e informada. Únicamente bajo esos preceptos podríamos concluir que no estaríamos hablando de una vulneración a la dignidad humana y al debido proceso constitucional.

Todavía es demasiado pronto para determinar con certeza cuáles son los aportes neurocientíficos al campo del derecho. Sin embargo, cada una de las técnicas mencionadas hacen parte de posibles pruebas periciales científicas que pueden ser aportadas a un proceso. Por ello, debemos valorar críticamente todos estos pretendidos avances que sin lugar a duda, pueden ayudar a los tribunales en su función jurisdiccional y a la consecución de una mayor o menor probabilidad de certeza, en relación con las proposiciones planteadas por las partes. Hoy en día es normal que, dentro de un proceso penal, exista un mayor predominio de la prueba testimonial frente a cualquier otro medio probatorio, especialmente frente a las pruebas novel.Es, de hecho, a partir de la valoración de esta prueba testimonial que, por lo general, los jueces penales toman sus decisiones. Sin embargo, se considera que, dadoslos avances que existen en relación con la psicología del testimonio y las llamadas trampas de la memoria, deberíamos replantearnos o estar más atentos con la fiabilidad que otorga una prueba testimonial y la capacidad de percepción de los testigos.

Para continuar con el hilo, vamos a mencionar algunos casos relevantes en los que la neurociencia se ha utilizado en el área judicial, en países como Estados Unidos y España, especialmente en el primero, país donde más se ha reportado el uso de la neurociencia como prueba:

- En 1978, Dan White se dirigió a su antiguo jefe y le pidió que le restituyera su empleo; cuando este se negó, White lo mató con un disparo, después caminó hasta la oficina de un supervisor y también lo asesinó. Los abogados de White sostuvieron en su defensa que, en el momento de cometer el crimen, él tenía sus capacidades mentales disminuidas y no había cometido un acto premeditado; lo que sucedía, en realidad, era que sus reiterados excesos con la comida muy azucarada habían causado estragos en la química de su cerebro. White fue condenado por homicidio voluntario sin premeditación y cumplió una condena de cinco años. Esa táctica de la defensa se conoció como la Defensa Twinkie. 
- Otro caso similar al anterior, conocido como la Defensa del Síndrome Premenstrual, es el de una cirujana que agredió a un policía: este la había parado por conducir en estado de embriaguez; ella quedó exonerada, porque su acción fue asociada con la rabia de sus hormonas.

- En 1983 se utilizó, por primera vez, en un juicio la técnica de la resonancia magnética funcional (FMRI) en el cerebro de un presunto asesino, acusado de secuestrar y matar a una niña de diez años. La defensa se sirvió de la técnica de neuroimágen para demostrar que su cliente padecía una psicopatía que le impedía controlar su comportamiento. De ese modo intentó evitar la pena de muerte.

- En el año 2013, el Juzgado de Violencia sobre la Mujer, número 2, de Zaragoza autorizó, mediante auto (confirmado por la Audiencia Provincial en 2014), la prueba neurológica llamada brainfingerprinting ("toma de huellas cerebrales”), a petición de la Policía Nacional, con el fin de ayudar a encontrar el cuerpo de la esposa del acusado. La brainfingerprinting, también es conocida como la prueba P300 y es una de las técnicas más prometedoras en cuanto a fiabilidad y utilidad en el ámbito judicial. Su fundamento reside en que diversos estímulos, tanto sensoriales como internos, provocan en el cerebro ciertas modificaciones de la actividad eléctrica registrada en el encefalograma, como secuencias de fluctuaciones $u$ ondas características (los "potenciales evocados"). Una de las ondas más estudiadas es la P300: se trata de una onda que aparece como un pico en un electroencefalograma, 300 milisegundos después de que se presente un estímulo ante un sujeto en ciertas condiciones. A partir de ella se ha desarrollado una técnica que permite someter al sujeto a un encefalograma y medir las respuestas de su cerebro ante estímulos como fotos, frases, etc., relacionadas con el delito que se investiga. Después, un programa informático es capaz de determinar el grado de probabilidad de que la información que se le ha mostrado sea conocida o no por este sujeto, con independencia -en principio - de sus manifestaciones verbales o su conducta intencional (Villamarín, 2015).

- En España se autorizó, por primera vez, a través de la vía judicial, la práctica de brainfingerpriting, dentro del proceso que se adelantó por el Juzgado de Violencia sobre la Mujer, número 2, de Zaragoza, en el caso de Antonio Losilla. Pilar Cebrián, de 51 años, desapareció en abril de 2012 en Ricla, una localidad zaragozana. Su marido, Antonio Losilla, tardó casi un mes en denunciarlo. La policía comenzó la investigación, porque intuyó un posible homicidio. Los restos de sangre hallados en el garaje del domicilio familiar fundaban las sospechas contra el marido, pero faltaba hallar el cadáver de Pilar Cebrián. El juez ordenó el ingreso de Losilla en prisión. El juez del Juzgado de Violencia sobre la Mujer ordenó la práctica de la P300, con la finalidad de hallar en la mente de Losilla indicios del lugar en el que podía hallarse el cuerpo sin vida de su esposa. Antonio Losilla confesó haber matado a su esposa, descuartizado su cuerpo y lanzar el cadáver en diversos contenedores de Almunia y Zaragoza.

- Otro ejemplo es el mediático caso de Marta del Castillo, en el que el Juzgado de Instrucción, número 4, de Sevilla, a petición de la Policía Judicial, autorizó la excarcelación temporal de Miguel Carcaño, ya condenado, para investigar la localización del cuerpo de la víctima. Una de las conclusiones de la prueba parece haber sido que el cuerpo de Marta del Castillo habría sido enterrado y no arrojado al río, pues el cerebro del sospechoso reaccionaba ante la visión de fotos de una escombrera (donde presuntamente estaría enterrada la víctima) y no ante fotos del río. Eso era, de hecho, lo que el propio Carcaño había declarado; así que la prueba confirmó, en este caso, su sinceridad (Villamarín, 2015).

\section{Referencias}

[Asociación Británica de Neurociencias. (2003). Neurociencias. La ciencia del cerebro: una introducción para jóvenes estudiantes. Recuperado de https://es.slideshare.net/alehlizarraga/neurociencias-15560160

Casafont, R. (2014). Viaje a tu cerebro. El arte de transformar tu mente. Barcelona: Grupo Zea. 
Gómez Pavajeau, C. (2017). Neurociencias y derecho. Bogotá: Editorial Nueva Jurídica.

Gonzales, D. (2013). ¿La tercera humillación? (Sobre neurociencia, filosofía y libre albedrío). Neurociencia y proceso judicial. Madrid: Marcial Pons.

Gonzales, D. (2015) “Neuropruebas” y filosofía. Jueces para la Democracia (84), 67-83.

Gonzales, D. (2018). Tres retos de la neurociencia para el Derecho penal. Anuario de Filosofía del Derecho (34), 43-72.

Lenin, V. I. (1948). Materialismo y empiriocriticismo. Montevideo: Ediciones Pueblos Unidos.

Luna, F. (2018). El mito del cientificismo en la valoración de la prueba científica. Jurídicas cuc, 14(1), 119-144. doi: http://dx.doi.org/10.17981/juridcuc.14.1.2018.6

Molina Galicia, R. (2013). Neurociencia y proceso judicial. Madrid: Marcial Pons.

Mora, F. y Sanguinetti, A. (2004). Diccionario de neurociencia. Madrid: Alianza Editorial.

National Academy of Science. (2009). Strengthening Forensic Science in the United States, Washington, the
National Academy Press. Recuperado de htpp://www. nap-edu/catalog/12589.html.

Picó I Junoy, J. (2013). La prueba del dolor. Neurociencia y proceso judicial. Madrid: Marcial Pons.

Rocha, C. (2013). Derecho y neurociencias. Bogotá: Ediciones Academia Colombiana de Jurisprudencia.

Sanguinetti, J. (2014). Neurociencia y filosofía del hombre. Madrid: Ediciones Palabra.

Strawson, P. (1995). Libertad y resentimiento. Barcelona: Paidós.

Taruffo, M. (2013). Proceso y neurociencia. En M. Taruffo y J. Nieva (dirs.), Neurociencia y proceso judicial. Madrid: Marcial Pons.

Vázquez Rojas, C. (2015). De la prueba científica a la prueba pericial. (1.a ed.). Madrid: Marcial Pons..

Villamarín López, M. (2014). Neurociencia y detección de la verdad y del engaño en el proceso penal. El uso del escáner cerebral (FMRI) y del brainfingerprinting (P300). Madrid: Marcial Pons. 